\title{
ESTIMATION OF GUGGULSTERONE-Z IN GOKSHURADI GUGGULU USING REVERSED-PHASE HIGH-PERFORMANCE LIQUID CHROMATOGRAPHY
}

\author{
KANAN G GAMIT, NIRAJ Y VYAS, NISHIT D PATEL, MANAN A RAVAL*
}

Department of Pharmacognosy and Phytochemistry, Ramanbhai Patel College of Pharmacy, Charotar University of Science and Technology, Changa, 388421, Anand, Gujarat, India. Email: mananraval.ph@charusat.ac.in

Received: 5 April 2018, Revised and Accepted: 06 July 2018

\section{ABSTRACT}

Objective: A study was aimed to estimate guggulsterone-Z (GZ) in Gokshuradi Guggulu (GG).

Methods: An analytical method was developed and validated using Waters Alliance high-performance liquid chromatography system (Empower software), equipped with photodiode array detector. Separation was achieved using Phenomenex, C-18 (250 mm $\times 4.6 \mathrm{~mm}, 5 \mu)$ column. Mobile phase consisted of acetonitrile:water $(70: 30, \mathrm{v} / \mathrm{v})$. Flow rate was set to $1 \mathrm{ml} / \mathrm{min}$ and detection was performed at $251 \mathrm{~nm}$.

Results and Discussion: Validation parameters such as linearity, precision, accuracy, limit of detection, limit of quantification, and robustness were performed. Amount of GZ was estimated using linearity equation.

Conclusion: GG was found to contain $0.815 \pm 0.03 \mathrm{~g} \% \mathrm{w} / \mathrm{w}$ GZ. Validated method may be used as one of the parameters to standardize the formulation.

Keywords: Gokshuradi Guggulu, Guggulsterone-Z, High-performance liquid chromatography.

(C) 2018 The Authors. Published by Innovare Academic Sciences Pvt Ltd. This is an open access article under the CC BY license (http://creativecommons. org/licenses/by/4. 0/) DOI: http://dx.doi.org/10.22159/ajpcr.2018.v11i11.26894

\section{INTRODUCTION}

Gokshuradi Guggulu (GG) is a solid formulation, prepared using Guggulu as basic ingredient. The formulation is official in Ayurvedic Formulary of India. Gokharu (Tribulus terrestris) and Guggulu (exudates from Commiphora wightii) are the major ingredients of GG. GG is used in the treatment of dysuria, urinary obstruction, excessive vaginal discharge, gout, spermatogenic, and vitiation of semen [1]. Guggulsterone is an active constituent of Guggulu, characterized as cis (E) and trans (Z) stereoisomers of 4,17(20)-pregnadiene-3,16-dione [2,3]. Chemical structure of guggulsterone-Z (GZ) is shown in Figure.1. GZ was first isolated from ethyl acetate fraction of gum resin of Commiphora mukul (known as Guggulu) belongs to family Burseraceae [4-7]. The oleo gum resin is traditionally used in the management of hypercholesterolemia and obesity [8-10]. Apart from this, Guggulu is used extensively as base in many Ayurveda formulations, commonly known as Guggulu.

Various physical parameters were evaluated for shodhit guggul [11]. Several analytical methods are reported for the estimation of GZ in different matrix present in combination with different phytoconstituents. Guggulsterone was estimated by high-performance liquid chromatography (HPLC) from its raw material C. wightii [12-14], rabbit plasma [15], and from a marketed herbal formulation [16]. Guggulsterone was also estimated using reversed-phase HPLC (RPHPLC) in few herbal tablet formulations [17]. GZ with gallic acid and piperine was estimated using HPLC-mass spectrometry (MS) [18]. High-performance thin-layer chromatography (HPTLC) method was developed to estimate guggulsterone from tablets [19], amount of GZ was estimated from Triphala Guggulu using HPTLC [20,21]. There has been no report of any chromatographic method for the estimation of GZ in GG; thus, it was planned to develop a chromatographic method for the estimation of GZ in GG.

\section{METHODS}

GG was manufactured by Sunder Pharmacy (GMP certified manufacturing unit associated with J and S Ayurveda College, Nadiad,
Gujarat, India) on our request. GZ (>95\%) was purchased from Natural Remedies, Bangalore, India. All solvents used were of HPLC grade and procured from Merck India. Water used was double distilled. The solvents were filtered through a $0.45 \mu \mathrm{m}$ filter (Millipore Bedford, MA, USA) and degassed in an ultrasonic bath (Remi Instruments, Mumbai, India) before use.

\section{Preparation of combined standard stock solution}

Accurately weighted, $10 \mathrm{mg} \mathrm{GZ}$ was dissolved in $5 \mathrm{ml}$ of methanol using sonication. The solution was diluted up to $10 \mathrm{ml}$ using methanol.

\section{Preparation of working standard solution}

Different volumes of standard stock solution were diluted using methanol to produce different dilutions in the range of $20-320 \mu \mathrm{g} / \mathrm{ml}$, for GZ.

\section{Preparation of sample solution}

GG was received in the form of compressed tablets. Tablets were grounded to powder using mortar and pestle. $50 \mathrm{~g}$ tablet powder was weighed accurately and transferred quantitatively to a $250 \mathrm{ml}$ round bottom flask and extracted using $50 \mathrm{ml}$ of chloroform for $2 \mathrm{~h}$. Mixture was allowed to cool at room temperature. Chloroform extract was collected. Procedure was repeated twice using $100 \mathrm{ml}$ of chloroform for $1 \mathrm{~h}$ each. Chloroform extracts were mixed together, filtered through Whatman filter paper and subjected to evaporation using rotary vacuum evaporator at $40^{\circ} \mathrm{C}$. Resulting semisolid mass was stored in a container and analyzed immediately after drying. $4 \mathrm{~g}$ of chloroform extract was dissolved in $50 \mathrm{ml}$ of methanol in a volumetric flask. This solution is diluted up to $50 \mathrm{ml}$ using methanol. $1 \mathrm{ml}$ of resultant solution as diluted up to $10 \mathrm{ml}$ using methanol. This solution was filtered using syringe filter to avoid the presence of insoluble extractives in sample solution. This clear solution was used as sample solution for the estimation of GZ and injected directly in HPLC system.

Development and optimization of chromatographic conditions Initially, reported HPLC-based analytical methods were adopted to separate peak of GZ in sample solution [12-17]. The studies revealed 
that none of the adopted analytical methods could separate peak corresponding to GZ from nearby peaks in sample solution. A new

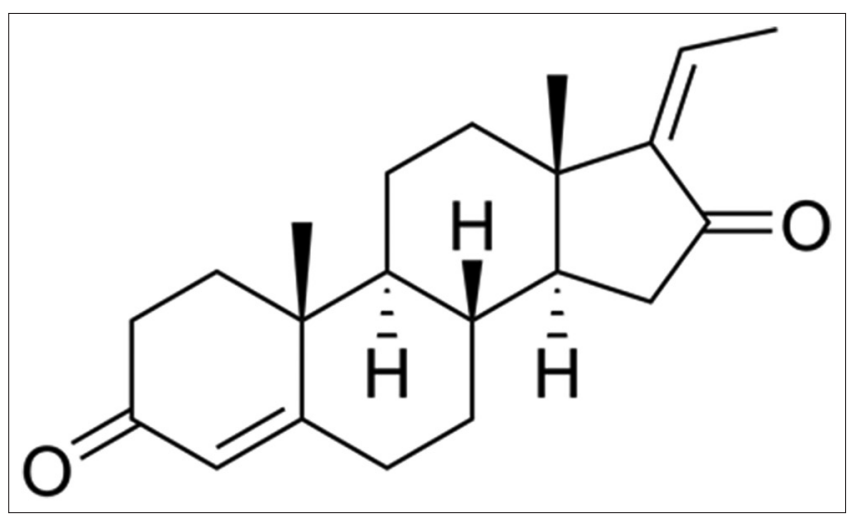

Fig. 1: Chemical structure of Guggulsterone-Z analytical method, thus, was developed by modifying the reported analytical method. It was kept in consideration that the proposed method should be isocratic and could be able to separate GZ peak at $\mathrm{R}_{\mathrm{T}}<10 \mathrm{~min}$, without affecting resolution. The peak should be Gaussian in shape and plates were sufficiently high to yield recommended value of repeatability. The results of the studies are shown in Fig. 2a and b, in the form of chromatogram.

\section{Validation of analytical method using HPLC}

The developed method was subjected to analytical method validation to evolve value for the parameters as mentioned in ICH guidelines. Details of the procedure adopted to validate the method are mentioned below.

\section{System suitability parameters (SSP)}

Repeatability, number of plates, resolution, capacity factor, and tailing were considered as SSP. Repeatability was measured from area of GZ peak from sample solution. Sample solution was subjected to HPLC analysis, by adopting optimized chromatographic conditions. Percentage relative standard deviation (RSD) of peak
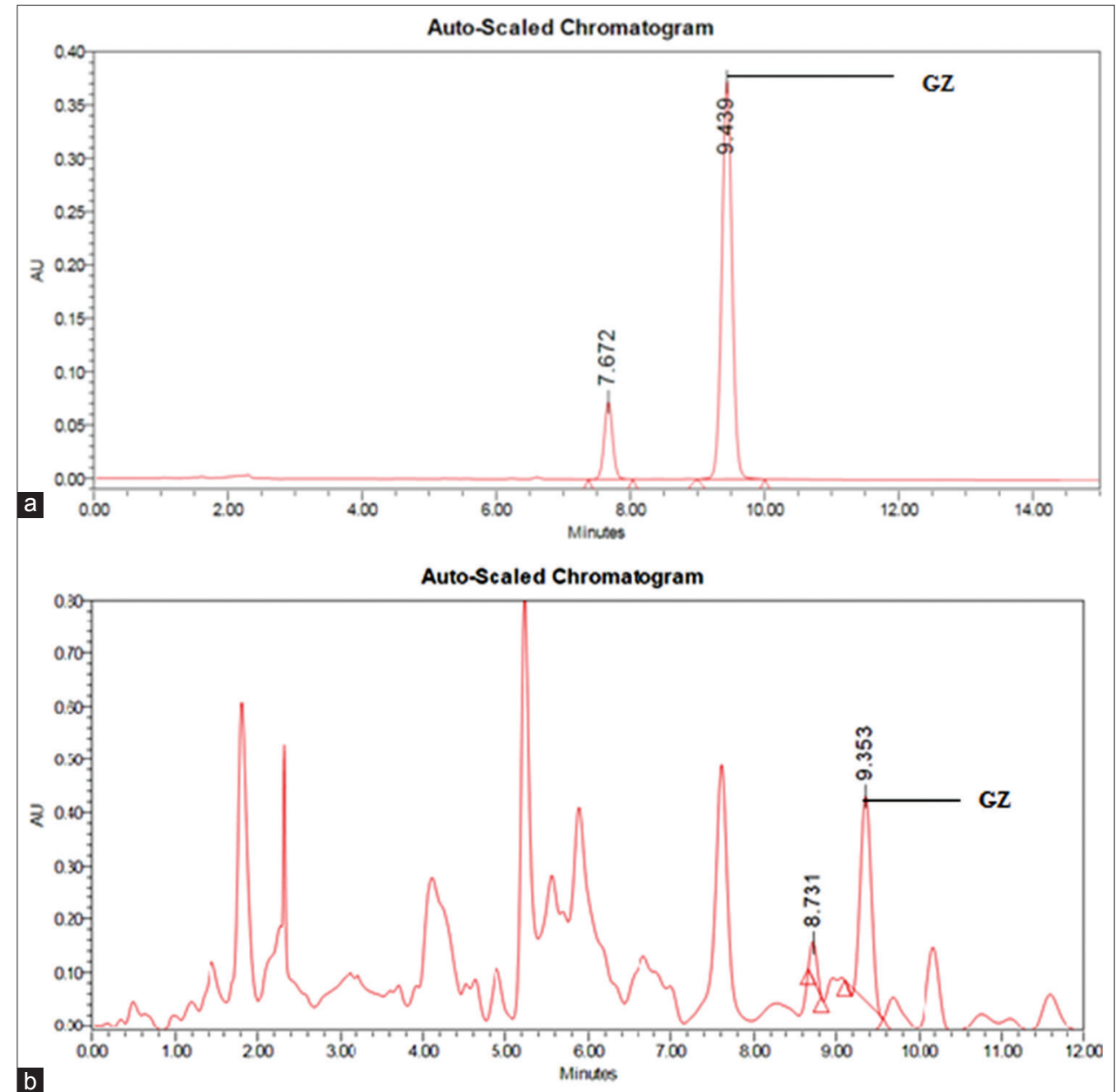

Fig. 2: (a) Chromatogram of guggulsterone-Z (GZ) in standard solution. (b) Chromatogram of GZ in chloroform extract of Gokshuradi Guggulu

Table 1: Value for selected SSP

\begin{tabular}{llll}
\hline Sr. No & Parameter & Value obtained & Recommended value [20] \\
\hline 1 & $\mathrm{R}_{\mathrm{T}}$ & 9.4 & - \\
2 & Repeatability (\% RSD) & 0.80 & $\mathrm{RSD}<1$ \\
3 & Number of plates & 23059.48 & $>2000$ \\
4 & Capacity factor & 9.38 & $>2$ \\
5 & Resolution & 3.06 & $\geq 1.5$ \\
6 & Tailing & 1.14 & $<2$ \\
\hline
\end{tabular}

RSD:Relative standard deviation 
area was determined. Number of plates, resolution, capacity factor, and tailing factors were determined for peak of GZ from recorded chromatogram of sample solution. The calculations were performed by methods recommended by USP. The results of the studies are shown in Table 1.

\section{Linearity}

Calibration range selected for the set of experiments was 20-320 $\mu \mathrm{g} / \mathrm{ml}$. Each concentration was injected for 6 times $(n=6)$. Calibration curve was constructed by plotting average peak area versus concentrations using the least square equation. The average value of regression coefficient $\left(\mathrm{r}^{2}\right)$, y-intercept (C), and slope of calibration curve (m) was calculated and shown in Table 2 .

\section{Precision}

Precision studies were performed by determining interday and intraday variation in area corresponding to GZ for particular concentration of GZ.

Three selected concentrations of GZ standard solution 40, 80, and $160 \mu \mathrm{g} / \mathrm{ml}$ were subjected to intraday and interday precision studies. The fixed volume was injected and chromatogram was recorded by following optimized chromatographic conditions. Each concentration was injected for 6 times in a day for intraday analysis and daily once for 6 days for intraday analysis. The area covered by GZ peak in each chromatogram was recorded. RSD value was determined for peak area corresponds to each concentration. The data for each concentration was paired with the data obtained for a particular concentration by injecting six injections consecutively by following optimized chromatographic conditions and percentage RSD for combined data set was determined as shown in Table 3 .

\section{Sensitivity}

Sensitivity of developed method for GZ was established in terms of limit of detection (LOD) and limit of quantification (LOQ). LOD and LOQ wereinitially estimated through determining $\mathrm{S} / \mathrm{N}$ ration, when injectingsolutions while establishing linearity for GZ. GZ concentration yielded $\mathrm{S} / \mathrm{N}$ value for GZ peak, near to three was considered LOD, and more near to 10 was considered as LOQ. Lately, exact value LOD and LOQ were determined using mathematical equation, with the help of SD for $y$-intercept for linearity equation and average value of slope.

\section{Accuracy}

The accuracy of the method was established by performing recovery studies, by adopting standard addition method. The studies were performed at three levels, 50, 100, and $150 \%$ of the working concentration of GZ in sample solutions. Known amount of GZ was spiked in pre-analyzed sample solution. Experiments were performed in triplicate and amount of GZ was determined. The percentage recovery was determined in each case and shown as average recovery along with SD for each level (Table 4).

\section{Selectivity}

Selectivity of developed method was established by comparing the contours recorded for GZ peak received in sample solution with those obtained for GZ peak received in standard solution, as shown in Fig. 3.

\section{Robustness}

The proposed HPLC method was tested for robustness by introducing deliberate but small alteration in critical chromatographic condition. Alteration in acetonitrile proportion in mobile phase (corresponding alteration in water proportion) $( \pm 3 \%)$, alteration in flow rate $( \pm 0.2)$, and alteration in selected wavelength $( \pm 2.0 \mathrm{~nm})$ were selected parameters. One alteration in a factor was introduced and chromatogram was recorded after injecting standard solution of GZ $(80 \mu \mathrm{g} / \mathrm{ml})$. Area and $\mathrm{R}_{\mathrm{T}}$ value for GZ peak were noted. Each experiment was performed thrice to generate data sets. Each such dataset was statistically compared with that generated by injecting GZ using optimized conditions, using ANOVA.

\section{RESULTS AND DISCUSSION}

The method was developed and validated using Waters Alliance HPLC system (Empower software), equipped with UV detector. Column was Phenomenex, C-18 column $(250 \mathrm{~mm} \times 4.6 \mathrm{~mm}, 5 \mu)$. Mobile phase consisted of acetonitrile:water $(70: 30, v / v)$. Flow rate was set at $1 \mathrm{ml} / \mathrm{min}$, injection volume was kept constant at $20 \mu \mathrm{l}$, and detection was performed at $251 \mathrm{~nm}$. As shown in Fig. 2a, sharp Gaussian peak corresponding to GZ was obtained in sample solution chromatogram. Retention time for GZ was 9.2 min. Fig. 2a and b showed chromatogram of GZ and chromatogram of GZ in chloroform extract of GG, respectively, showing retention time $9.4 \mathrm{~min}$. The chromatogram generated for sample solution might serve as one of the identifying parameters for GG.

Table 2: Linearity data for GZ peak

\begin{tabular}{lcclll}
\hline Analyte & Slope $(\mathrm{m})$ Mean \pm SD & Confidence interval & $\begin{array}{l}\text { y-intercept } \\
(\mathbf{C}) \text { Mean } \pm \text { SD }\end{array}$ & Confidence interval & $\begin{array}{l}\text { RegressionCoefficient }\left(r^{2}\right) \\
\text { Mean } \pm \text { SD }\end{array}$ \\
\hline GZ & $53089.5 \pm 114.1258$ & $52997.83-53181.17$ & $74958.5 \pm 9334.35$ & $67460.42-82456.58$ & $0.9975 \pm 0.0012$ \\
\hline
\end{tabular}

n=6. GZ: Guggulsterone-Z, SD: Standard deviation

Table 3: Precision of analytical method for GZ

\begin{tabular}{lll}
\hline GZ concentration & $\begin{array}{l}\text { Variation in peak area of GZ determined on single } \\
\text { day (intraday) (\%RSD) }\end{array}$ & $\begin{array}{l}\text { Variation in peak area of GZ determined on six } \\
\text { different days (interday) (\%RSD) }\end{array}$ \\
\hline $40 \mu \mathrm{g} / \mathrm{ml}$ & 0.13 & 0.38 \\
$80 \mu \mathrm{g} / \mathrm{ml}$ & 0.14 & 0.28 \\
$160 \mu \mathrm{g} / \mathrm{ml}$ & 0.08 & 0.11 \\
\hline
\end{tabular}

GZ: Guggulsterone-Z, RSD: Relative standard deviation

Table 4: Recovery studies of GZ

\begin{tabular}{|c|c|c|c|c|}
\hline Sr. No & $\%$ GZ spiked & Conc. of GZ determined in solution $\mathrm{Avg} \pm \mathrm{SD}(\mu \mathrm{g} / \mathrm{ml})$ & $\%$ Amount recovered \pm SD & $\%$ Average recovery \\
\hline 1 & 0 & $81.54 \pm 0.25$ & - & - \\
\hline 2 & $49 \%$ & $116.55 \pm 1.34$ & $95.79 \pm 1.11$ & $95.89 \%$ \\
\hline 3 & $98 \%$ & $155.32 \pm 0.16$ & $96.04 \pm 0.10$ & \\
\hline 4 & $148 \%$ & $193.40 \pm 1.34$ & $95.84 \pm 0.67$ & \\
\hline
\end{tabular}




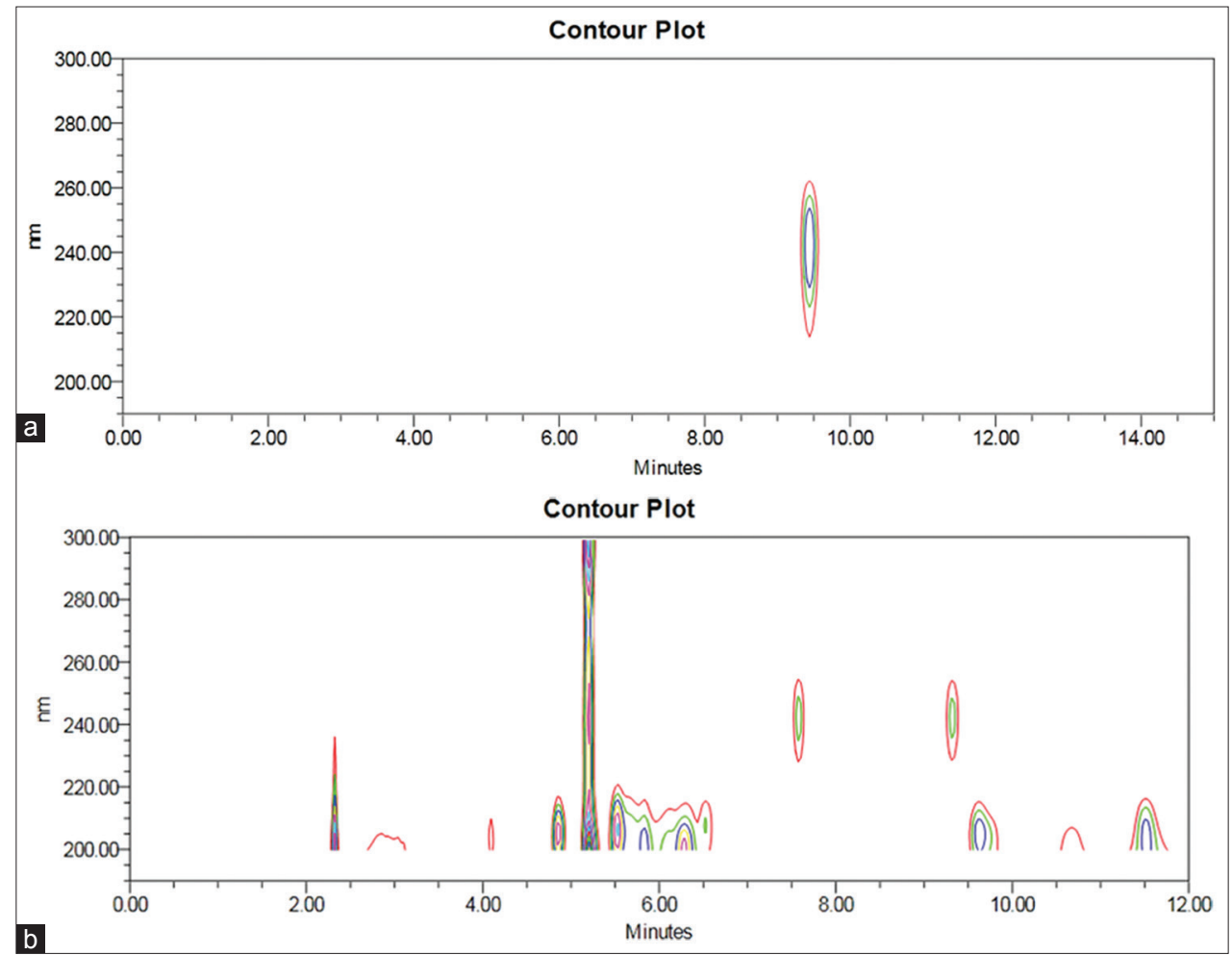

Fig. 3 (a) Contour of guggulsterone (GZ) in standard solution. (b) Contour of GZ in chloroform extract of Gokshuradi Guggulu

SSP parameters were also evolved as shown in Table 1. Percentage RSD value $<1.0$ for GZ peak confirmed that the variation in the peak area was within acceptable limit. The higher values of plats suggested that the peak obtained was Gaussian as well as sharp. The capacity factor value, more than 5.0 ensured that appropriate time was provided for interaction to happen with stationary phase. Resolution higher than 1.5 confirmed that the peak of GZ in sample solution was separated property from nearby peak, to be analyzed quantitatively. Tailing value near to 1.0 showed that the column packing was intact. As shown in figure, the studies ensured that the developed method could be able to resolute GZ peak.

The correlation coefficient value for plot of concentration of GZ and corresponding peak area was found approaching 1.0, determined using the least square regression analysis. The $\mathrm{C}$ value was also comparatively low. These two ensured the linearity of area for the concentration range selected for the studies.

Precision of the developed method was established in the form of variation in peaks of GZ while performing intraday and interday analysis. The results, in Table 3, showed that percentage RSD value for all three selected concentrations was within the recommended limit. Intraday precision and interday precision were found to be $0.11-0.38 \%$ RSD and $0.08-0.13 \%$ RSD, respectively, as shown in Table 3 . The low values of percentage RSD confirmed that the method was precise enough to carry out routine analysis of GZ. It was also noted that there was comparatively higher variation noted in case of interday, which suggested the probable degradation of GZ in solution, though acceptable, it should be kept in consideration.

LOD and LOQ values were determined to establish sensitivity of the developed analytical method for GZ. LOD and LOQ were found to be $1.4 \mu \mathrm{g} / \mathrm{ml}$ and $4.4 \mu \mathrm{g} / \mathrm{ml}$, respectively, for GZ.

Selectivity of the developed method for GZ was ensured by matching the shape of contour produced for GZ peak in sample chromatogram with that in chromatogram of standard GZ solution. As shown in Fig. 2, the contours were matching, as well as UV spectra of peak were also matched. It ensured that the peak made up of spectroscopically homogenous material.

Accuracy of the developed method was assessed by performing recovery studies using standard addition method. The pre-analyzed sample solution was spiked with known concentration of GZ, and the sample solution was reanalyzed. Percentage recovery was calculated, found near to $95.89 \%$, as shown in Table 4 . The closeness of recovery nearly to $100 \%$ with low percentage RSD (i.e., <2) within acceptance range ensured accuracy. The studies confirmed that the developed analytical method was accurate and free from the interference of other material used in formulation.

Selectivity of the analytical method was the ability to assess only the analyte, GZ in the presence of other components which were present. Sample solution of GG contained many different related or unrelated (chemically) phytoconstituents. Selectivity was ensured by recording contour plots, for the peaks. These contour plots corresponding to GZ peak in chromatogram of sample solution were compared with that recorded for GZ peak in chromatogram of GZ standard. The contour plots are shown in Fig. 3a and b.

Robustness was determined initially, by incorporating deliberate small alteration in selected chromatographic parameters, one at a time. The studies showed that within the ranges selected the data sets of peak area for $\mathrm{GZ}$ and $\mathrm{R}_{\mathrm{T}}$ were not statistically different from those obtained after receiving the peak and $\mathrm{R}_{\mathrm{T}}$, after following optimized chromatographic conditions. This confirmed that robustness of analytical method within the selected ranges. It was revealed from robustness studies that when acetonitrile proportion alteration was $\pm 3 \% \mathrm{v} / \mathrm{v}$, alteration in flow rate was $\pm 0.2 \mathrm{ml} / \mathrm{min}$, and wavelength was within $\pm 2 \mathrm{~nm}$ of reported value, there was no statistically significant alteration in $\mathrm{R}_{\mathrm{T}}$ and peak area of GZ.

The estimation of GZ in GG sample solution was performed 3 times, each sample solution was prepared from an independent experiment and area for GZ peak was noted. GZ was, then, estimated from the equation obtained from linearity study. The amount of GZ found in GG was $0.815 \pm 0.03 \mathrm{~g} \% \mathrm{w} / \mathrm{w}$. 


\section{CONCLUSION}

A validated HPLC method was developed for the quantification of GZ from an Ayurvedic formulation GG and validated. The developed analytical method could separate GZ from sample matrix without introducing gradient elution or without introducing $\mathrm{pH}$ adjustment. The validation studies confirmed that the developed method had linear response in terms of area of GZ peak, for the selected range of GZ concentrations. The developed method was precise, accurate, and sensitive enough for the purpose. The developed method could tolerate alterations in chromatographic parameters, without affecting the performance. This method, thus, may be introduced as one of the standardization parameters for the assessment of quality of GG.

\section{ACKNOWLEDGMENT}

The authors would like to express their thanks and gratitude to J. S. Ayurvedic College, Nadiad, for providing Gokshuradi Guggulu. The authors are thankful to the Charotar University of Science and Technology management for providing facility, encouragement, and support in research.

\section{AUTHOR'S CONTRIBUTION}

Kanan Gamit involved throughout the research work in the laboratory. Manan Raval provided his knowledge about chromatography and supported to evaluate data. Nishit Patel and Niraj Vyas supported to carry out experiments on HPLC.

\section{CONFLICTS OF INTEREST}

The authors declare that they have no conflicts of interest.

\section{REFERENCES}

1. Government of India, Ministry of Health and Family Welfare. Anonymous. The Ayurvedic Pharmacopoeia of India. Part II, Vol. II, $1^{\text {st }}$ ed. (Formulations). New Delhi, India: Government of India, Ministry of Health and Family Welfare, Dept of AYUSH; 2008. p. 112-4.

2. Bajaj AG, Dev S. Chemistry of ayurvedic crude drugs. Tetrahedrone 1982;38:2949-54.

3. Sahni S, Hepfinger CA, Sauer KA. Guggulu lipid used in hyperlipidemia: Case report and review of the literature. Am J Health Syst Pharm 2005;62:1690-2.

4. Dev S. A modern look at an age old ayurvedic drug- Guggul. Sci Age 1987;1987:13-8

5. Satyavati GV, Dwarakanath C, Tripathi SN. Experimental studies on the hypocholesterolemic effect of Commiphora mukul. Engl. (Guggul). Ind J Med Res 1969;57:1950-62.

6. Urizar NL, Moore DD. Gugulipid: A natural cholesterol-lowering agent. Ann Rev Nutr 2003;23:303-13.

7. The Indian Pharmacopoeia Commission. Anonymous. Indian
Pharmacopoeia. $6^{\text {th }}$ ed. Vol. 3. Ghaziabad: The Indian Pharmacopoeia Commission; 2010. p. 25046

8. Latha BP, Reddy IR, Ismail SM, Vijaya T. Medicinal plants and their derivatives as potential source in treatment of obesity. Asian J Exp Biol Sci 2010;1:71927.

9. Saxena G, Singh SP, Pal R, Singh S, Pratap R, Nath C. Gugulipid, an extract of Commiphora whighitii with lipidlowering properties, has protective effects against Streptozotocininduced memory deficits in mice. Pharm Biochem Behav 2007;86:797805.

10. Gujral ML, Saxena K, Tangri KK, Amma MK, Roy AK. Anti-arthritic and anti-inflammatory activity of gum Guggul (Basalsamodenron mukul Hook). Ind J Physiol Pharm 1960;40:26773.

11. Patel MA, Acharya SR, Macwan CP, Patel TB, Suhagia BN. Evaluation of physico-chemical parameters of different Shodhit guggul. Int J Pharm Pharm Sci 2017;9:247-51.

12. Kulhari A, Sheorayan A, Chaudhury A, Sarkar S, Kalia RK. Quantitative determination of guggulsterone in existing natural populations of Commiphora wightii(Arn.) Bhandari for identification of germ plasm having higher guggulsterone content. Physiol Mol Biol Plants2015;21:71-81.

13. Vyas KY, Shukla VJ, Galib, Prajapati PK. Comparative physicochemical profiles of Fresh (Naveena) and Old (Purana) Guggulu (Commiphorawightii (Arn.) Bhandari) a pilot study. J Ayur Herb Med 2015;1:61-5.

14. Indian council of Medical Research. Anonymus. Quality Standards of Indian Medicinal Plants. New Diehl: Indian council of Medical Research; 2005. p. 177-88.

15. Bhatt RS, Kumar D, Chhonker YS, Jain G K. Simultaneous estimation of E-and Z-isomers of guggulsterone in rabbit plasma using liquid chromatography tandem mass spectrometry and its application to pharmacokinetic study. Biomed Chromatogr 2011;25:1054-60.

16. Patil P, Nipanikar S, Bhusnar H, Nagore D. Simultaneous estimation of guggulsterone E, GUGGULSTERONE Z, KBA, AKBA, with a ferin $A$ and 6-Gingerol by Using HPLC-DAD method from ariflex tablet Formulation. Int J Pharm Sci Drug Res 2015;7:89-95.

17. Akhade MS, Agrawal PA, Laddha KS. Development and validation of RPHPLC method for simultaneous estimation of picroside I, plumbagin, and Zguggulsterone in tablet formulation. Ind J Pharm Sci 2013;75:476-82.

18. Muguli G, Vadaparthi PR, Ramesh B, Gowda V, Paramesh R, Jadhav AN, et al. A novel highperformance liquid chromatographyelectron spray ionizationmass spectrometry method for simultaneous determination of guggulsterones, piperine and gallic acid in Triphalaguggulu. Pharm Mag 2015;11 Supplement 1:66-72.

19. Mogal N, Agrawal M. Simultaneous determination of diosgenin and guggulsterone-Z in Gokshuradi guggulu tablet by high-performance thin-layer chromatography. Asian J Bio Pharm Sci 2015;5:32-4.

20. Vyas J, Itankar P, Tauqeer M, Kelkar A, Agrawal M. Development of HPTLC method for estimation of piperine, Guggulsterone $\mathrm{E}$ and $\mathrm{Z}$ in polyherbal formulation. Pharm J 2013;5:259-64.

21. Itankar P, Nagulwar DB, BhatlawandeB. Physical, phytochemical and chromatographic evaluation of Triphala guggul Tablets. Int J Pharm Phytopharmacol Res 2015;4:306-9. 